\title{
Effect of different dietary omega-3/omega-6 fatty acid ratios on reproduction in male rats
}

\author{
Lin Yan, Xiao-long Bai, Zheng-feng Fang, Lian-qiang Che, Sheng-yu Xu and De Wu*
}

\begin{abstract}
Background: Beneficial effects of omega-3 polyunsaturated fatty acids (n-3 PUFAs) on the reproduction of male animals are widely described in the literature. However, there is little information about the effect of $n-3 / n-6$ PUFA ratios on male health and reproduction. The aim of this study was to investigate the effects of diets with different n-3/n-6 PUFA ratios on the reproductive performance of male rats.
\end{abstract}

Methods: Eighty male Sprague Dawley (SD) rats were supplemented with diets containing different n-3/n-6 PUFA ratios $(0.13,0.40,0.85,1.52$ and 2.85$)$ for 60 days. Half of the rats in each group were sacrificed on day 60 , and the other half were chosen to mate with female mice to assess the effects of $n-3 / n-6$ ratios on reproductive performance.

Results: Sperm density and sperm motility of the 1.52 group were higher than other groups $(P<.05)$, and the development of testis and the morphological structure of sperm in the 1.52 group were better than other groups. Furthermore, a higher litter size and birth weights of offspring were observed in the 1.52 group. Additionally, serum reproductive hormone levels were significantly affected by the $n-3 / n-6$ ratios.

Conclusion: These findings demonstrated that a balanced $n-3 / n-6$ ratio was important in male rat reproduction. Therefore there is a necessity to determine an appropriate n-3/n-6 PUFA ratio in man and different male animals in the future.

Keywords: Omega-3 fatty acids, Omega-6 fatty acids, Ratio, Male, Reproduction

\section{Background}

Sperm cells contain very high proportions of polyunsaturated fatty acids (PUFA) [1], and normal spermatozoa possess a higher percentage of the most representative PUFA (C22:6 n-3) than those detected in blood serum phospholipids and in other cell membranes [2]. The lipid composition, the degree of PUFA unsaturation, and the proportion of sperm PUFA have been shown to affect sperm quantity [2-4]. Animals cannot synthesize n-6 or $\mathrm{n}-3$ fatty acids de novo because of a lack of the appropriate fatty acid desaturase enzymes. The n-6 PUFA and the $n-3$ PUFA therefore need to be provided in the diet as these PUFAs are essential for numerous processes including growth, reproduction, vision, and brain development [5].

\footnotetext{
* Correspondence: pig2pig@sina.com

Key Laboratory for Animal Disease Resistance Nutrition of the Ministry of Education, and Animal Nutrition Institute of Sichuan Agricultural University, Ya'an 625014, China
}

(c) 2013 Yan et al.; licensee BioMed Central Ltd. This is an Open Access article distributed under the terms of the Creative Commons Attribution License (http://creativecommons.org/licenses/by/2.0), which permits unrestricted use, distribution, and reproduction in any medium, provided the original work is properly cited.
Studies in men [4] and boars [1,6,7] have demonstrated the benefits of $n-3$ fatty acids on male reproductive capacity. While, other studies in humans [8] and boars [9] did not show any effect of n-3 PUFA supplementation on semen quality or quantity post-ejaculation. However, Am-in N [10] pointed out that the ratios of n-3/n-6 PUFAs in boar sperm were negatively correlated with sperm motility, viability, normal morphology, and normal plasma membranes, which suggested that the appropriate ratio of n-3/n-6 PUFAs in males was important for sperm quality. Although there is little information about the effect of $n-3 / n-6$ ratios on male reproduction, other researchers have shown the beneficial role of an appropriate dietary n-3/n-6 ratio for embryo development and health. Dietary intake of a low ratio of n-6/n-3 PUFAs of about 1-2:1 during both maternal pregnancy and lactation may be more beneficial for early fetal development [11]. Santillán et al. [12] suggested that the maintenance of an adequate $n-3 / n-6$ 
ratio was necessary for the optimal growth and development of murine offspring and several metabolic parameters in adulthood [13], including bone development [14]. Health benefits may be achieved by lowering dietary $n-6$ /n-3 PUFAs even in a high fat diet medium [15]. However, modern dietary trends have increased this ratio from 10:1 to 25:1 in westernized human populations [16]. Therefore, in both human and animal diets there are grounds for maintaining the proper ratio of n-6 and n-3 PUFAs dietary intakes to promote reproduction. However, little is known about the effects of different ratios of n-6 and n-3 PUFAs on sperm quality and fertility, although both positive and negative actions are theoretically possible. Because of the lack of research data, additional research was needed. Thus, the objective of the present study was to determine the effects of different ratios of n-6 and n-3 PUFA intakes on semen quality, breeding ability, and serum reproductive hormone levels.

\section{Methods}

Animals and diets

All experimental protocols were approved by the Animal Care and Use Committee of the Sichuan Agricultural University, and were in accordance with the National Research Council's Guide for the Care and Use of Laboratory Animals. Eighty male Sprague Dawley (SD) rats and forty female SD rats used in the present study were purchased from Chengdu Da Shuo Biotech Co., Ltd [License: SCXK 2008-24] with an initial age of 90-days old. Female rats were fed a commercial diet for mating with the males to further determine the effect of different ratios of n-3/n-6 PUFAs on litter size and birth weight of male rats' offspring. Animals were housed individually in clear metallic cages within a bio-bubble in a temperature-controlled room $\left(21-23^{\circ} \mathrm{C}\right)$ with a $12 \mathrm{~h}$ light/dark cycle.

The male rats were fed diets containing 7\% oil from soybean and flaxseed for 60 days. The basic formulation of the experimental diets (Table 1) contained supplemental ratios of soybean oil (SO): flaxseed oil (FO), namely $100: 0,75: 25,50: 50,25: 75$, and $0: 100$. The ratios of dietary n-3/n-6 PUFAs were $0.13,0.40,0.85,1.52$, and 2.85. The fatty acid compositions of the oils used in this study are presented in Table 2 and the fatty acid compositions of the diets shown in Table 3 . Rats were allowed free access to food and water.

\section{Collection of blood and tissue samples}

Rats were anesthetized in sealed jar containing cotton moistened by $350 \mu \mathrm{l}$ isoflurane at 30 and 60 days. Tail vein blood was collected and centrifuged at $4000 \mathrm{rpm}$ for $10 \mathrm{~min}$ at $4^{\circ} \mathrm{C}$ for the collection of serum and stored at $-20^{\circ} \mathrm{C}$ until analysis.
Table 1 Composition and nutrient levels of basal diets

\begin{tabular}{ll}
\hline Ingredients & Percentage(\%) \\
\hline Corn starch & 39.75 \\
Casein & 20.00 \\
Gelatinization starch & 13.20 \\
Sucrose & 10.00 \\
Cellulose & 5.00 \\
Soybean oil & 7.00 \\
Linseed oil & 0.00 \\
Mineral premix ${ }^{1}$ & 1.00 \\
Vitamin premix $^{2}$ & 3.50 \\
Choline Chloride $^{2}$ & 0.30 \\
L-Cys $^{2}$ & 0.25 \\
t-BHQ & \\
Total & 0.0014 \\
\hline
\end{tabular}

${ }_{1}$ Provided per kg of diet: Calcium 5000 mg; Phosphorus 1561 mg; Kalium 3600 mg; Natrium 1019 mg; Chlorine 1517 mg; Magnesium 510 mg; Ferrum 35 mg; Znic 30 mg; Manganese 10 mg; Copper 6 mg; I 0.2 mg;

Selenium $0.15 \mathrm{mg}$.

${ }^{2}$ Provided per kg of diet: $\mathrm{VD}_{3} 1000 \mathrm{IU} ; \mathrm{VK}_{3} 0.75 \mathrm{mg} ; \mathrm{VB}_{1} 6.0 \mathrm{mg} ; \mathrm{VB}_{2} 7.0 \mathrm{mg}$; $\mathrm{VB}_{6} 6.0 \mathrm{mg} ; \mathrm{VB}_{12} 0.02 \mathrm{mg}$; nicotinic acid $30.0 \mathrm{mg}$; D-calcium pantothenate

$15.3 \mathrm{mg}$; folic acid $2.0 \mathrm{mg}$; biotin $0.2 \mathrm{mg}$.

${ }^{3} \mathrm{t}-\mathrm{BHQ}$, tert-butyl hydroquinone.

\section{Semen quality and reproductive performance}

Half of the rats in each treatment group were anesthetized and sacrificed for collection of testis, epididymis, and vas deferens on day 60. The epididymides were dissected in $2 \mathrm{ml}$ normal saline $(0.9 \% \mathrm{NaCl})$; incubated at $37^{\circ} \mathrm{C}$, and sperm motility was evaluated by the

Table 2 Fatty acid composition of soybean oil and flaxseed oil

\begin{tabular}{llll}
\hline Fatty Acid & & Soybean Oil & Flaxseed Oil \\
\hline Myristic(\%) & $14: 0$ & 0.06 & 0.03 \\
Palmitic(\%) & $16: 0$ & 10.89 & 5.90 \\
Palmitoleic(\%) & $16: 1 \mathrm{n}-7$ & 0.14 & 0.11 \\
Stearic(\%) & $18: 0$ & 3.25 & 4.36 \\
Oleic(\%) & $18: 1 \mathrm{n}-9$ & 24.5 & 22.96 \\
Linoleic(\%) & $18: 2 \mathrm{n}-6$ & 53.41 & 16.16 \\
Linolenic(\%) & $18: 3 \mathrm{n}-3$ & 7.34 & 49.93 \\
Eicosanoic(\%) & $20: 1 \mathrm{n}-9$ & 0.02 & 0.17 \\
Eicosanoic(\%) & $20: 1 \mathrm{n}-7$ & 0.04 & 0.17 \\
Eicosapentaenoic(\%) & $20: 5 \mathrm{n}-3$ & - & - \\
Docosahexaenoic(\%) & $22: 6 \mathrm{n}-3$ & - & - \\
Other fatty acid(\%) & & 0.35 & 10.21 \\
Total fatty acid & & 100 & 10.16 \\
Total n-3PUFAs & & 7.34 & 49.93 \\
Total n-6PUFAs & & 53.41 & $1: 7.30$ \\
n-3:n-6 & & &
\end{tabular}

Note: Values in the table are measured values $(n=4)$. 
Table 3 Fatty acid composition of the $\operatorname{diet}(\mathrm{mg} / \mathrm{g})$

\begin{tabular}{|c|c|c|c|c|c|}
\hline \multirow{2}{*}{$\frac{\text { Items }}{\text { SO:FO }}$} & \multicolumn{5}{|l|}{ Ratio of SO:FO } \\
\hline & 100:0(Diet 1) & 75:25(Diet 2) & 50:50(Diet 3) & 25:75(Diet 4) & 0:100(Diet 5) \\
\hline $\mathrm{C} 12: 0$ & 0.07 & 0.06 & 0.07 & 0.07 & 0.04 \\
\hline C14:0 & 0.35 & 0.32 & 0.35 & 0.34 & 0.22 \\
\hline C14:1 & 0.01 & 0.01 & 0.01 & 0.01 & 0.01 \\
\hline C16:0 & 7.55 & 6.31 & 6.29 & 5.52 & 3.82 \\
\hline C16:1 & 0.11 & 0.10 & 0.10 & 0.10 & 0.08 \\
\hline C18:0 & 2.87 & 2.53 & 2.75 & 2.64 & 2.03 \\
\hline C18:1 & 0.27 & 0.23 & 0.24 & 0.23 & 0.16 \\
\hline C18:1n9 & 12.51 & 11.01 & 11.68 & 11.28 & 8.96 \\
\hline C18:1n7 & 0.80 & 0.65 & 0.62 & 0.53 & 0.37 \\
\hline C18:2n6 & 25.94 & 20.14 & 18.37 & 14.09 & 8.13 \\
\hline C18:3n6 & 0.29 & 0.01 & 0.02 & 0.32 & 0.29 \\
\hline C18:3n3 & 3.15 & 7.92 & 15.44 & 21.82 & 23.94 \\
\hline C20:0 & 0.22 & 0.18 & 0.17 & 0.14 & 0.08 \\
\hline C20:1 & 0.12 & 0.11 & 0.12 & 0.12 & 0.10 \\
\hline$C 20: 2$ & 0.05 & 0.04 & 0.04 & 0.03 & 0.02 \\
\hline C20:4n6 & - & - & 0.01 & 0.01 & 0.01 \\
\hline$C 20: 3$ & - & 0.01 & 0.02 & 0.02 & 0.02 \\
\hline$C 20: 5 n 3$ & 0.25 & 0.19 & 0.17 & 0.13 & 0.07 \\
\hline$C 22: 0$ & 0.04 & 0.02 & 0.03 & 0.02 & 0.02 \\
\hline C22:1 & 0.06 & 0.05 & 0.05 & 0.04 & 0.03 \\
\hline$C 22: 4 n 6$ & 0.01 & 0.01 & 0.01 & 0.02 & 0.02 \\
\hline C24:0 & 0.12 & 0.09 & 0.09 & 0.08 & 0.06 \\
\hline$C 22: 5 n 3$ & 0.04 & 0.02 & 0.03 & 0.02 & 0.02 \\
\hline$C 22: 6 n 3$ & 0.01 & 0.01 & 0.01 & 0.01 & 0.01 \\
\hline C24:1 & 0.03 & 0.02 & 0.01 & 0.01 & 0.01 \\
\hline Total n-3PUFAs & 3.45 & 8.14 & 15.65 & 21.98 & 24.04 \\
\hline Total n-6PUFAs & 26.24 & 20.17 & 18.41 & 14.44 & 8.44 \\
\hline Ratio of n-3:n-6 & 0.13 & 0.40 & 0.85 & 1.52 & 2.85 \\
\hline
\end{tabular}

Note: Values in the table are measured values.

procedures described in previous publication [17]. At least 200 spermatozoa and 5 fields were assessed for each specimen $(n=8)$, and the percentages of motile and progressively motile spermatozoa were determined. Sperm density was determined by using a hemocytometer count according to the method modified from that described by Taylor et al. [18] and Egbunike et al. [19]. Mean spermatozoa density was obtained by counting from 5 squares of a hemocytometer. Morphological abnormalities of the sperm head in 8 rats of every group were assessed essentially according to the criteria of Wyrobek and Bruce [20], and the results presented as percentages. Half of the male rats in each treatment group on day 61 were mated with female rats in a ratio of $1: 1$. All female rats were provided the same commercial standard chow during pregnancy. The pregnancy rate, litter size, and birth weight in the female rats were observed.

Measurement of serum gonadotropin-releasing hormone (Gnrh), luteinizing hormone (LH), follicle stimulating hormone (FSH), and testosterone (T)

GnRH, LH, FSH and T concentrations in serum were measured using an ELISA kit (R\&D Systems, Inc., Minneapolis, MN, USA) according to the manufacturer's protocol. All assays were performed in 96-well plates and the absorbance was measured at $450 \mathrm{~nm}$ by using an enzyme-labeled meter (Thermo Electron Corporation, Varioskan TM, Waltham, MA, USA). The levels of hormones were determined from the standard curve and expressed as picograms per milligram protein. 
Table 4 Effects of different ratio of $\mathrm{N}-3 / \mathrm{N}-6$ on the weight gain and feed intake of male SD rats

\begin{tabular}{|c|c|c|c|c|c|}
\hline Items & Diet 1 & Diet 2 & Diet 3 & Diet 4 & Diet 5 \\
\hline Ratio of n-3/n-6 & 0.13 & 0.40 & 0.85 & 1.52 & 2.85 \\
\hline Initial Body weight(g) & $316 \pm 12$ & $316 \pm 14$ & $312 \pm 12$ & $315 \pm 10$ & $314 \pm 13$ \\
\hline Final weight(g) & $388 \pm 10^{\mathrm{a}}$ & $395 \pm 12^{a}$ & $405 \pm 11^{\mathrm{ab}}$ & $421 \pm 15^{b}$ & $417 \pm 12^{b}$ \\
\hline Weight gain(g) & $71 \pm 4^{\mathrm{a}}$ & $79 \pm 3^{a}$ & $92 \pm 6^{b}$ & $106 \pm 5^{c}$ & $103 \pm 5^{b c}$ \\
\hline Food intake (g/day) & $22.26 \pm 2.04$ & $22.13 \pm 1.95$ & $22.39 \pm 2.11$ & $23.32 \pm 3.02$ & $23.95 \pm 2.48$ \\
\hline
\end{tabular}

Data were presented as means \pm standard deviation $(n=16)$, and value in the same row with different superscript letters denotes significant difference $(p<0.05)$.

\section{Lipid analysis}

The fatty acid compositions of the diets (oils and treatment diets) were evaluated using HP6890 GC-FID gas chromatography by the Analysis and Testing Center of China Agricultural University according to a modified method [10].

Testis and sperm electron microscopic examination After male rats were anesthetized with ether, both testes of each rat were removed without epididymis and fresh weights taken. For electron microscopy, the right testis was fixed by perfusion with fixative containing $5 \%$ glutaraldehyde buffered with $0.16 \mathrm{~mol} / \mathrm{L}$ s-collidine buffer, $\mathrm{pH} 7.4$, for $15 \mathrm{~min}$ [21]. A $1 \mathrm{~mm}$ thick transverse slice vertical to the long axis of the testis was taken from the middle portion of the organ, cut into approximately $1 \mathrm{~mm}$ cubes and immersed in the same fixative for $2 \mathrm{~h}$, washed with the same buffer, dehydrated in ethanol and embedded in Epon 812. A series of ultra-thin sections were cut on the LKB-Huxley ultramicrotome (LKB, Bromma, Sweden), with a diamond knife and stained with uranyl acetate and lead citrate,then examined and photographed using H-600 A-2 Jeol 1200 Ex-II electron microscopy (JEOL Ltd., Tokyo, Japan).

\section{Statistics}

Data were analyzed using SPSS 11.5 statistical package (V8.1, SAS Institute Inc., Cary, NC) and presented as mean \pm SEM. Multiple comparisons by DUNCAN analysis were performed to determine statistical differences among groups. Results were considered significant at $P<0.05$ for all tests.

\section{Results}

Effects of different ratios of N-3/N-6 PUFAs on the weight gain and feed intake of male SD rats

As shown in Table 4, there were no significant differences in the initial body weights and average daily food intakes. Weight gain tended to increase as the ratio of n-3/n-6 PUFAs increased and the rats fed diets 4 and 5 had significantly $(P<0.05)$ higher weight gains when compared with rats fed diet 1 and diet 2 .

\section{Effects of different ratios of N-3/N-6 PUFAs on semen characteristics of male SD rats}

There was no significant difference in testis index among groups $(P>0.05)$. Results of semen characteristics are shown in Table 5 . The sperm density of the diet 4 group was significantly higher than the diet 1 and diet 3 groups $(P<0.05)$, but there was no significant differences between animals in the diet 2 and 5 groups. Meanwhile, the sperm motility in the diet 4 group was higher than other groups $(P<0.05)$, and there were no significant differences among diet groups 1, 2 and 3. All sperm head, mid-piece, and tail anomalies were considered sperm deformations. The sperm deformity ratio was significantly influenced by the ratio of n-3/n-6 PUFAs. The sperm deformity rate tended to decrease with the increasing $\mathrm{n}-3 / \mathrm{n}-6$ ratio $(P<0.05)$, and was significantly lower in rats fed diets 4 and 5 compared with those fed other diets.

Effects of different ratios of N-3/N-6 PUFAs on histological and ultra-structural changes

As seen in Figure 1, testicular seminiferous tubules epithelium and spermatogonia of the underlying epithelial

Table 5 Effects of different ratio of N-3/N-6 on semen characteristics of male SD rats

\begin{tabular}{llllll}
\hline Items & Diet 1 & Diet 2 & Diet 3 & Diet 4 & Diet 5 \\
\hline Ratio of $\mathrm{n}-3 / \mathrm{n}-6$ & 0.13 & 0.40 & 0.85 & 1.52 & 2.85 \\
Testis index & $11.22 \pm 1.83$ & $11.14 \pm 1.17$ & $10.74 \pm 0.98$ & $10.78 \pm 0.80$ & $10.54 \pm 0.77$ \\
Sperm density $\left(\times 10^{6} \mathrm{spz} / \mathrm{mL}\right)$ & $41.00 \pm 8.60^{\mathrm{c}}$ & $50.00 \pm 2.09^{\mathrm{ab}}$ & $44.50 \pm 5.28^{\mathrm{bc}}$ & $54.67 \pm 8.93^{\mathrm{a}}$ & $50.83 \pm 8.42^{\mathrm{ab}}$ \\
Motility (\%) & $66.67 \pm 2.58^{\mathrm{c}}$ & $66.33 \pm 2.50^{\mathrm{c}}$ & $68.83 \pm 1.47^{\mathrm{c}}$ & $82.33 \pm 5.20^{\mathrm{a}}$ & $74.50 \pm 3.45^{\mathrm{b}}$ \\
Sperm deformity ratio (\%) & $8.47 \pm 1.21^{\mathrm{a}}$ & $8.65 \pm 1.88^{\mathrm{a}}$ & $6.68 \pm 1.39^{\mathrm{b}}$ & $3.16 \pm 0.73^{\mathrm{c}}$ & $4.17 \pm 0.75^{\mathrm{c}}$ \\
\hline
\end{tabular}

Testis index = testis weight $(\mathrm{mg}) /$ body weight $(\mathrm{g})$.

Note: Data are presented as means \pm standard deviation $(n=8)$, and means in the same row with different superscript letters denotes significant difference $(p<0.05)$. 


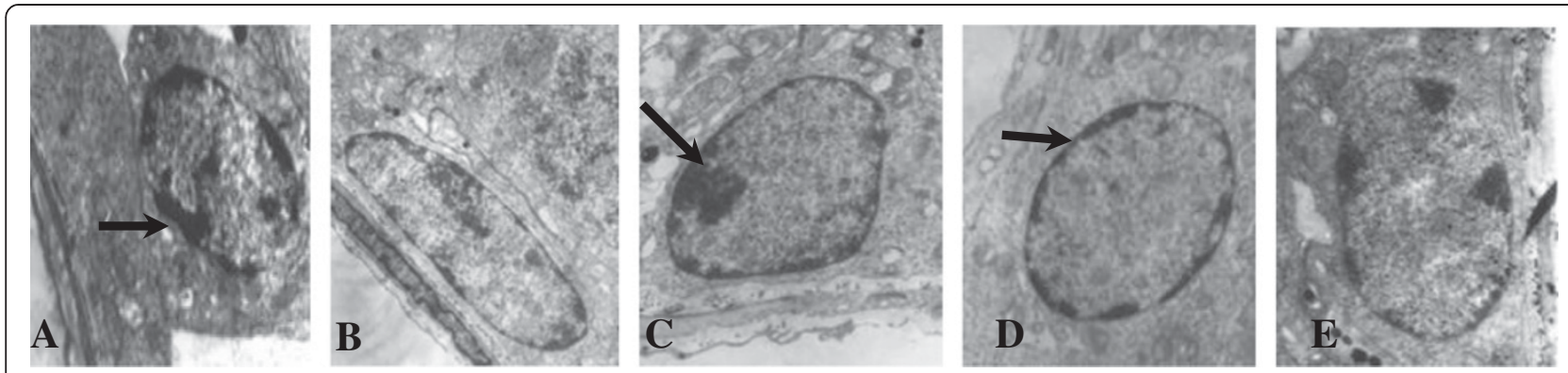

Figure 1 Electron micrograph of a portion of testicular seminiferous tubules epithelium and spermatogonia of the epithelial bottom in rat testis. $\times 80000$; A, Diet 1 (0.13); B, Diet 2 (0.4); C, Diet 3 (0.85); D, Diet 4 (1.52); E: Diet 5 (2.85).

cells developed normally; there were chromatin clumps along the nuclear membrane. Compared with the control group, better spermatogonial development and more uniform distribution of chromatin around the nuclear membrane was observed in the group with a n-3/n-6 PUFA ratio of 1.52 (diet 4). Spermatocytes developed better than control group (Figure 2). The bridge between adjacent spermatocytes was visible and nucleoli were prominent, mitochondria abundant, and lysosomes observed in the cytoplasm in diets containing FO groups.

The structural integrity of mature sperm heads was presented in every group (Figure 3 ), while sperm tail abnormalities was more serious in the control group. Integral acrosomal cap and tail outer dense fibers and mitochondrial sheaths were observed in the testis in the group consuming a n-3/n-6 PUFA ratio of 1.52 (diet 4). Effects of the n-3/n-6 ratio on sperm tails histology are shown in Figure 4. The central axoneme, nine dense peripheral axonemal fibers, and the mitochondrial sheath in cross-sections of the middle piece of the sperm tails in the flaxseed oil supplemented groups were clearly visible compared with the control group, and were evenly distributed in the group consuming a n-3/n-6 PUFA ratio of 1.52 .

\section{Effects of different ratios of N-3/N-6 PUFAs on reproductive capacity}

Effects of n-3/n-6 PUFA ratios on reproductive capacity are shown in Table 6 . The litter size in diet 1 group was the lowest, and improved with increasing n-3/n-6 levels $(P<0.05)$, while there was no significant difference between the ratio 1.52 and 2.85 groups, indicating the importance of an appropriate ratio of $n-3 / n-6$ for normal reproductive function in male rats. A similar result was observed for birth weight, which was the lowest in diet 1 group and increased with the enhancing of the dietary n-3/n-6 PUFA ratio $(P<0.05)$.

\section{Effects of different ratios of $\mathrm{N}-3 / \mathrm{N}-6$ PUFAs on the serum hormone levels}

The data for total circulating reproductive hormones are shown in Table 7. The GnRH concentrations were significantly higher in rats fed diet 4 compared with other groups on day 30, and increased with the increasing of the n-3/n-6 PUFA ratios on day $60(P<0.05)$. A similar trend was observed for LH, FSH, and T concentrations. The $\mathrm{LH}, \mathrm{FSH}$, and $\mathrm{T}$ concentrations in rats fed diet 4 were higher than other groups on days 30 and 60 , and

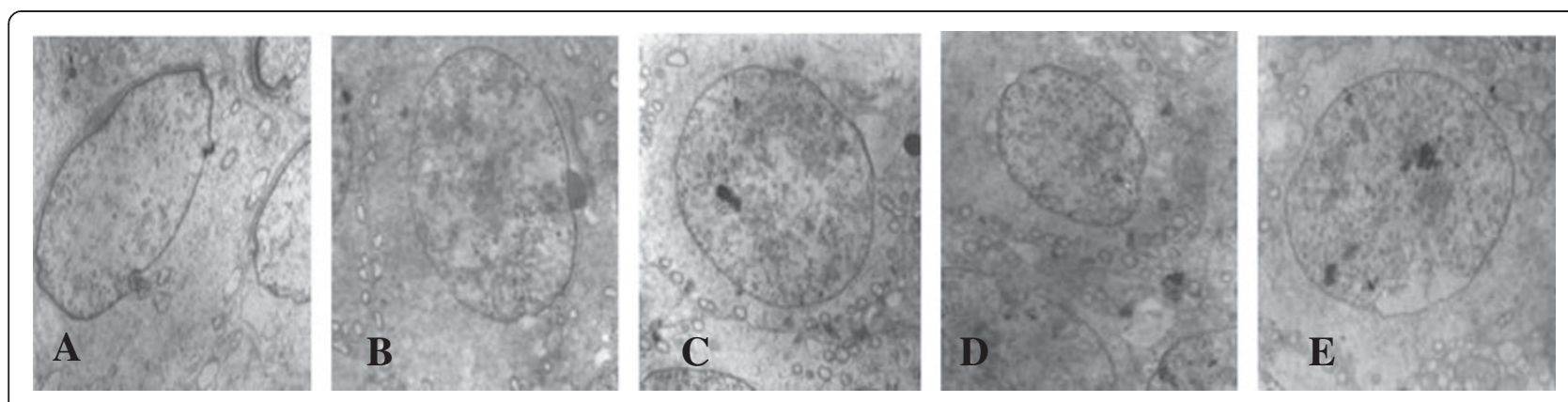

Figure 2 Effects of different ratio of n-3/n-6 on spermatocytes histology of rats testis. $\times 60000$. A, Diet 1 (0.13); B, Diet $2(0.4)$; C, Diet $3(0.85)$; D, Diet 4 (1.52); E: Diet 5 (2.85). 


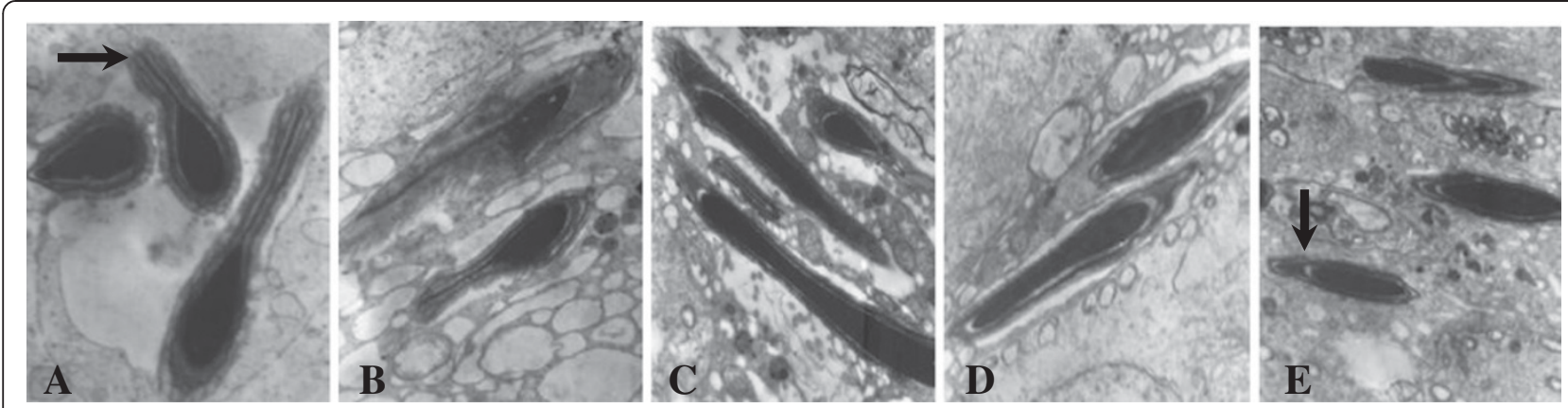

Figure 3 Effects of different ratio of $\mathbf{n}-\mathbf{3} / \mathbf{n}-\mathbf{6}$ on sperm cells histology. $\times 100000$. A, Diet 1 (0.13); B, Diet 2 (0.4); C, Diet 3 (0.85); D, Diet 4 (1.52); E: Diet 5 (2.85).

no difference was observed in groups fed diet 1,2 , and 3 $(P>0.05)$.

\section{Discussion}

The purpose of this study was to evaluate the impact of different ratios of $n-3 / n-6$ PUFAs on sperm quality and reproductive performance, and provide the basis for determining the appropriate $n-3 / n-6$ PUFA ratio for male animals. Accumulating evidence from studies in men $[4,22]$ and animals $[1,6,7]$ indicated that consumption of n-3 fatty acids was beneficial to male reproductive capacity, but the appropriate ratio of $n-3 / n-6$ PUFAs for male reproduction was still not known.

The results of this study showed that different ratios of n-3/n-6 PUFAs had no effects on the testis index, but improved sperm quality. With an increasing $n-3 / n-6$ PUFA ratio, sperm density and motility were increased, and the sperm deformity rate tended to decrease. Additionally, better histological and ultra-structural changes of testis and sperm were observed in the group consuming a n-3/n-6 PUFA ratio of 1.52 . It was reported that boar diets supplemented with $30 \mathrm{~g} / \mathrm{kg}$ of tuna oil or fish oil (rich in long chain n-3 fatty acids) increased sperm motility and the content of normal acrosome and sperm cell morphology [1], improving the total number of sperm per ejaculation, and the membrane integrity of sperm [6]. More recently, it was found that boar diets fortified with n-3 rich fatty acid additives enhanced the sperm total number of average ejaculations, and the morphological integrity of sperm was improved [7]. Furthermore, the ratio of $n-3 / n-6$ PUFAs in boar sperm were positively correlated with sperm motility, viability, normal morphology, and normal plasma membranes [10], and excessive n-3 PUFA supplementation decreased the sperm density and motility in our experiment, which indicated the importance of the $n-6 / n-3$ PUFA ratio in sperm quality.

Research has shown that diets containing distinct lipid sources differentially modified the lipid contents of the sperm head and body membranes, resulting in significant improvement in semen quality [23,24]. Al-Daraji et al. [23] found the proportion of $n-3$ fatty acids in spermatozoa from Japanese male quail fed fish oil compared with corn oil was higher $(9.6 \%$ vs. $4.3 \%)$ and that of $\mathrm{n}-6$ fatty acids was lower $(22.4 \%$ vs. $33.3 \%)$. The sperm of flaxseed-fed rabbits had an n-3/n-6 ratio two times higher compared with the control because of the increasing dietary n-3/n- 6 ratio [25]. In addition, it was reported that diets containing different lipid sources changed the lipid contents of sperm, mainly affecting the sperm head and body membranes [24]. It is worth noting that the dietary $n-3 / n-6$ PUFA ratio affected the lipid composition of perch semen. However, no significant effects of changes in the $n-3 / n-6$ ratios were
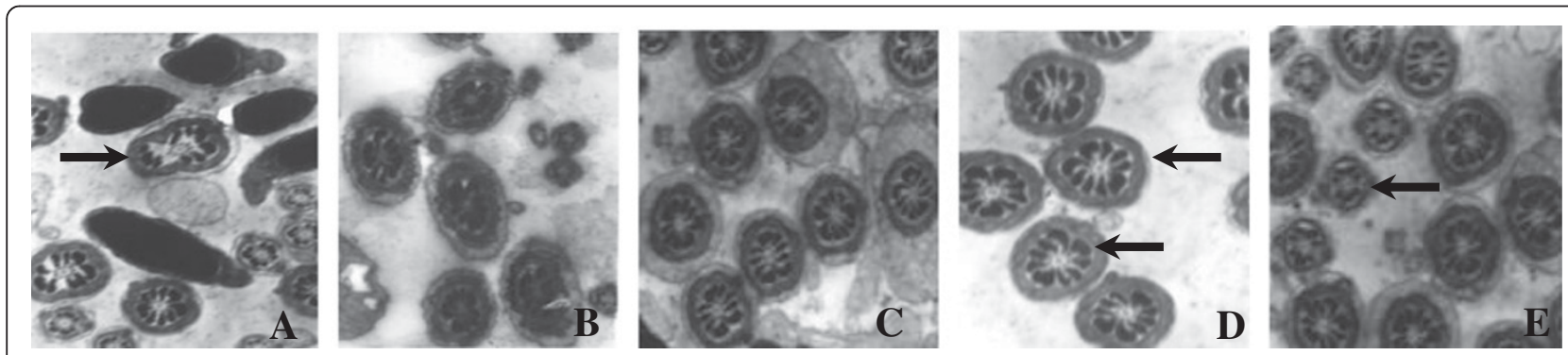

Figure 4 Effects of different ratio of $n-3 / n-6$ on cross sections of middle piece of sperm tails histology in rat testis. $\times 150000$. A, Diet 1 (0.13); B, Diet 2 (0.4); C, Diet 3 (0.85); D, Diet 4 (1.52); E: Diet 5 (2.85). 
Table 6 Effects of different ratio of $\mathrm{N}-3 / \mathrm{N}-6$ on reproductive capacity of male SD rats

\begin{tabular}{llllll}
\hline Items & Diet 1 & Diet 2 & Diet 3 & Diet 4 & Diet 5 \\
\hline Ratio of $\mathrm{n}-3 / \mathrm{n}-6$ & 0.13 & 0.40 & 0.85 & 1.52 & 2.85 \\
Litter size(n) & $8.88 \pm 1.75^{\mathrm{c}}$ & $9.33 \pm 1.03^{\mathrm{bc}}$ & $9.17 \pm 2.03^{\mathrm{c}}$ & $12.3 \pm 1.75^{\mathrm{a}}$ & $11.33 \pm 2.06^{\mathrm{ab}}$ \\
Birth weight (g) & $5.83 \pm 0.54^{\mathrm{b}}$ & $5.93 \pm 0.28^{\mathrm{b}}$ & $6.22 \pm 0.15^{\mathrm{ab}}$ & $6.43 \pm 0.39^{\mathrm{a}}$ & $6.57 \pm 0.28^{\mathrm{a}}$ \\
\hline
\end{tabular}

Note: Data are presented as means \pm standard deviation $(n=8)$, and means in the same row with different superscript letters denotes significant difference $(p<0.05)$.

observed in the sperm volume density and spermatozoa motility when the $n-3 / n-6$ ratios were 0.2 and 7.0 respectively [26], indicating high correlations between these changes in dietary lipid content and sperm lipid concentration, and that an appropriate n-3/n-6 PUFA ratio was important for sperm quality. Therefore, we speculate that a possible reason for improving sperm quality in our experiment should be related to the changes in sperm composition induced by different fatty acid compositions in the diets.

In fact, very few studies have been conducted to examine the effects of the ratio of $n-3 / n-6$ PUFAs on male reproduction. It is known that both $n-6$ and n-3 PUFAs can influence reproductive processes. In this study, we found that litter size and birth weight increased with increasing n-3/n-6 PUFA ratios; lower or higher $n-3 / n-6$ ratios have adverse effects on reproduction, which was consistent with the results of sperm quality and sperm morphology. Blesbois [27] found that increasing the ratio of n-3/n-6 PUFAs in the diet can enhance the hatching rates of male turkeys at 48-58 weeks by nearly 2 points. Higher rates of embryonic and larval survival were observed in male European sea bass fed PUFAenriched diets [28]. Similarly, studies conducted in females also have observed positive effects of diets rich in n-3 PUFA on reproductive performance. It was demonstrated that supplementing n-3 fatty acids from fish oil in the diet of sows improved early embryo survival [29], thereby increased piglet litter sizes [30,31]. Meanwhile, the content and variety of the maternal intake of PUFAs were shown to be associated with weight gain and growth of infants, particularly in preterm infants [32,33]. Therefore, these results confirmed that maintaining an appropriate n-3/n-6 PUFA ratio was very important for reproductive performance in males and females.

Twenty-carbon PUFAs are the direct precursors of a large group of physiologically active compounds [34]. From our results, we found that by increasing the ratio of n-3/n-6 PUFAs, the concentrations of GnRH, FSH, $\mathrm{LH}$, and $\mathrm{T}$ increased. However, levels of these hormones dropped when the $n-3 / n-6$ PUFA ratio was over 1.52 , suggesting a close relationship between the n-3/n-6 PUFA ratio and the reproductive endocrine system. In males, the hypothalamus secretes $\mathrm{GnRH}$, which binds to $\mathrm{GnRH}$ receptors on the gonadotropic cells to stimulate the release of FSH and $\mathrm{LH}$ into the circulation. $\mathrm{LH}$ stimulates the interstitial cells located in the testes to produce testosterone, and FSH plays a role in spermatogenesis [35]. The reduction of LH pulse frequency of mature male sheep after reduction of feed intake has been observed [36], while putting rams on a high energy diet increased $\mathrm{GnRH}$ pulse frequency, testicular mass, and sperm production [37]. The increase of LH and FSH levels in rats after supplementation with Nigella sativa oil may be the result of a direct effect of the oil on the hypothalamus, which in turn increases GnRH [38]. Similar effects also were observed on levels of plasma testosterone, which were higher when the same diet was available ad libitum than in restricted growth lambs from 7 to 17 weeks. Ad libitum feeding stimulated increased plasma FSH and LH levels above values for the restricted growth group [39]. Bubenik et al. [40] reported that LH levels in high-protein/low-energy fed deer were higher than those fed high-protein/high-energy diets in summer. Furthermore, lower energy intakes during pregnancy significantly reduced peak levels of testosterone in deer male offspring [40], suggesting that nutrition not only affected the reproductive hormone secretion and reproduction function of the male animal, but also may affected reproductive development and function in future generations.

Table 7 Effects of different ratio of $\mathrm{N}-3 / \mathrm{N}-6$ on the serum hormone levels of male SD rats

\begin{tabular}{lllll}
\hline Groups & GnRH(ng/L) & LH(ng/L) & FSH(IU/L) & T(nmol/L) \\
\hline 30d & & & & \\
Diet 1 & $10.14 \pm 1.06^{\mathrm{b}}$ & $17.37 \pm 1.30^{\mathrm{b}}$ & $5.76 \pm 0.92^{\mathrm{b}}$ & $40.23 \pm 1.12^{\mathrm{b}}$ \\
Diet 2 & $10.07 \pm 0.98^{\mathrm{b}}$ & $17.76 \pm 1.09^{\mathrm{b}}$ & $5.55 \pm 0.56^{\mathrm{b}}$ & $40.29 \pm 2.00^{\mathrm{b}}$ \\
Diet 3 & $10.45 \pm 1.69^{\mathrm{b}}$ & $18.43 \pm 1.47^{\mathrm{b}}$ & $6.50 \pm 1.20^{\mathrm{ab}}$ & $46.62 \pm 8.06^{\mathrm{b}}$ \\
Diet 4 & $12.29 \pm 0.46^{\mathrm{a}}$ & $20.39 \pm 0.55^{\mathrm{a}}$ & $7.12 \pm 0.99^{\mathrm{a}}$ & $57.16 \pm 4.06^{\mathrm{a}}$ \\
Diet 5 & $10.54 \pm 1.56^{\mathrm{b}}$ & $18.33 \pm 1.57^{\mathrm{b}}$ & $6.19 \pm 0.86^{\mathrm{ab}}$ & $45.81 \pm 7.85^{\mathrm{b}}$ \\
60 d & & & & \\
Diet 1 & $10.36 \pm 1.30^{\mathrm{c}}$ & $15.87 \pm 0.96^{\mathrm{c}}$ & $6.26 \pm 0.48^{\mathrm{b}}$ & $40.01 \pm 1.73^{\mathrm{c}}$ \\
Diet 2 & $10.48 \pm 0.74^{\mathrm{bc}}$ & $16.04 \pm 0.99^{\mathrm{c}}$ & $6.17 \pm 1.10^{\mathrm{b}}$ & $42.36 \pm 4.76^{\mathrm{bc}}$ \\
Diet 3 & $11.01 \pm 1.60^{\mathrm{abc}}$ & $16.08 \pm 1.24^{\mathrm{c}}$ & $5.57 \pm 0.98^{\mathrm{b}}$ & $39.86 \pm 5.39^{\mathrm{c}}$ \\
Diet 4 & $11.93 \pm 0.97^{\mathrm{ab}}$ & $20.13 \pm 0.93^{\mathrm{a}}$ & $7.39 \pm 1.06^{\mathrm{a}}$ & $51.28 \pm 3.82^{\mathrm{a}}$ \\
Diet 5 & $12.20 \pm 1.51^{\mathrm{a}}$ & $18.13 \pm 1.76^{\mathrm{b}}$ & $5.46 \pm 0.46^{\mathrm{b}}$ & $47.15 \pm 5.25^{\mathrm{ab}}$ \\
\hline
\end{tabular}

$\mathrm{GnRH}$, gonadotropin-releasing hormone; $\mathrm{LH}$, luteinizing Hormone; FSH, follicle stimulating hormone; $\mathrm{T}$, testosterone.

Note: Data are presented as means \pm standard deviation $(n=6)$, and means in the same columns with different superscript letters denotes significant difference $(p<0.05)$. 
Modern dietary trends have increased the $n-6 / n-3$ PUFA ratio from 10:1 to 25:1 in westernized human populations [16]. Tian et al. [11] suggested that a diet with a low ratio of $n-3 / n-6$ PUFAs at about 0.5-1:1 during both maternal pregnancy and lactation may be more beneficial for early development; our results regarding the ratio of $n-3 / n-6$ PUFA at 1.52 are consistent with the previous findings. Other studies have reported that diets with high $n-6 / n-3$ PUFA ratios may enhance the risk for both depression and inflammatory diseases [41], while a low ratio of $n-6 / n-3$ PUFAs improved growth and development of murine offspring [13], as well as several metabolic parameters in adulthood [14] and human health $[16,19]$. Results of this study clearly indicate that the ratios of $n-3 / n-6$ PUFAs in the diet have a great influence on sperm quality traits and reproductive performance, and that a n-3/n-6 PUFAs ratio of 1.52 improved the reproductive capacity of male rats.

\section{Conclusions}

In conclusion, intake of an appropriate n-3/n-6 PUFA ratio in the diet of rats increased sperm characteristics and enhanced the structure integrity of testis and sperm, thereby improving reproductive performance, which may be related to changes in hormone metabolism. These findings provide a sound basis that a balanced n-3/n- 6 PUFA ratio will be beneficial to male reproduction. Therefore there is a necessity to determine an appropriate $n-3 / n-6$ PUFA ratio in man and different male animals in the future.

\section{Abbreviations}

n-3/n-6 PUFA: Omega-3/omega-6 polyunsaturated fatty acid;

GnRH: Gonadotropin-releasing hormone; LH: Luteinizing hormone; FSH: Follicle stimulating hormone; T: Testosterone.

\section{Competing interests}

The authors declare that they have no competing interests.

\section{Authors' contributions \\ $Y L$ was involved in the study, experimental design, data analysis, and manuscript writing. XLB was involved in the experimental design and animal experiments. ZFF was involved in the experimental design and data analysis. LQC was involved in study design and data interpretation. SYX was involved in data analysis. The group leader of the Institute of Animal Nutrition, DW, was involved in the study design and manuscript editing. All authors have read and approved the final manuscript.}

\section{Acknowledgments}

The present research was supported by National Natural Science Foundation of China (31072044). We are grateful to all the volunteers who participated in the study for their time and effort.

Received: 24 December 2012 Accepted: 28 February 2013 Published: 13 March 2013

\section{References}

1. Rooke JA, Shao CC, Speake BK: Effects of feeding tuna oil on the lipid composition of pig spermatozoa and in vitro characteristics of semen. Reproduction 2001, 121:315-322.

2. Lenzi A, Picardo M, Gandini L, et al: Lipids of the sperm plasma membrane: from polyunsaturated fatty acids considered as markers of sperm function to possible scavenger therapy. Hum Reprod 1996, 2:246-256

3. Cerolini S, Surai P, Mangiagalli G, Cavalchini LG, Noble RC: Effect of $n-3$ and n-6 fatty acid supplemented diets and vitamin E level on semen quality in cockerels. Br Poult Sci 2000, 41:S8-S10.

4. Safarinejad MR, Safarinejad S: The roles of omega-3 and omega- 6 fatty acids in idiopathic male infertility. Asian J Androl 2012, 14:514-515.

5. Gurr Ml, Harwood JL, Frayn KN: Lipid Biochemistry: An Introduction[M]. 5th edition. Oxford, UK: Blackwell Science Ltd; 2002.

6. Strzezek J, Fraser L, Kuklińska M, Dziekońska A, Lecewicz M: Effects of dietary supplementation with polyunsaturated fatty acids and antioxidants on biochemical characteristics of boar semen. Reprod Biol 2004, 4:271-287.

7. Estienne MJ, Harper AF, Crawford RJ: Dietary supplementation with a source of omega-3 fatty acids increases sperm number and the duration of ejaculation in boars. Theriogenology 2008, 70:70-76.

8. Conquer JA, Martin JB, Tummon I, Watson L, Tekpetey F: Effect of DHA supplementation on DHA status and sperm motility in asthenozoospermic males. Lipids 2000, 35:149-154.

9. Castellano CA, Audet I, Bailey JL, Chouinard PY, Laforest JP, Matte JJ: Effect of dietary n-3 fatty acids (fish oils) on boar reproduction and semen quality. J Anim Sci 2010, 88:2346-2355.

10. Am-in N, Kirkwood RN, Techakumphu M, Tantasuparuk W: Lipid profiles of sperm and seminal plasma from boars having normal or low sperm motility. Theriogenology 2011, 75:897-903.

11. Tian C, Fan C, Liu X, Xu F, Qi K: Brain histological changes in young mice submitted to diets with different ratios of $n-6 / n-3$ polyunsaturated fatty acids during maternal pregnancy and lactation. Clin Nutr 2011, 30:659-667.

12. Santillán ME, Vincenti LM, Martini AC, de Cuneo MF, Ruiz RD, Mangeaud A, Stutz G: Developmental and neurobehavioral effects of perinatal exposure to diets with different omega-6:omega-3 ratios in mice. Nutrition 2010, 26:423-431.

13. Korotkova M, Gabrielsson BG, Holmäng A, Larsson BM, Hanson LA, Strandvik $B:$ Gender-related long-term effects in adult rats by perinatal dietary ratio of n-6/n-3 fatty acids. Am J Physiol Regul Integr Comp Physiol 2005, 288:R575-R579.

14. Korotkova M, Ohlsson C, Hanson LA, Strandvik B: Dietary n-6:n-3 fatty acid ratio in the perinatal period affects bone parameters in adult female rats. Br J Nutr 2004, 92:643-648.

15. Riediger ND, Othman R, Fitz E, Pierce GN, Suh M, Moghadasian MH: Low n-6:n-3 fatty acid ratio, with fish- or flaxseed oil, in a high fat diet improves plasma lipids and beneficially alters tissue fatty acid composition in mice. Eur J Nutr 2008, 47:153-160.

16. Simopoulos AP: Omega-3 fatty acids in health and disease and in growth and development. Am J Clin Nutr 1991, 54:438-463.

17. Wang S, Wang G, Barton BE, Murphy T, Huang HFS: Impaired sperm function after spinal cord injury in the rat is associated with altered cyclic adenosine monophosphate signaling. J Androl 2005, 26:592-600.

18. Taylor GT, Weiss J, Komitowski D: Reproductive physiology and penile papillae morphology of rats after sexual experience. J Endocrinol 1983, 98:155-163.

19. Egbunike GN, Elemo AO: Testicular and epididymal sperm reserves of crossbred European boars raised and maintained in the humid tropics. J Reprod Fertil 1978, 54:245-248.

20. Wyrobek AJ, Bruce WR: Chemical induction of sperm shape abnormalities in mice and human. Proc Natl Acad Sci USA 1975, 72:4425-4429.

21. Ichihara I, Kawamura H, Pelliniemi L: Ultrastructure and morphometry of testicular Leydig cells and the interstitial components correlated with testosterone in aging rats. Cell Tissue Res 1993, 271:241-255.

22. Safarinejad MR, Hosseini SY, Dadkhah F, Asgari MA: Relationship of omega3 and omega- 6 fatty acids with semen characteristics, and anti-oxidant status of seminal plasma: a comparison between fertile and infertile men. Clin Nutr 2010, 29:100-105.

23. Al-Daraji HJ, Al-Mashadani HA, Al-Hayani WK, Al-Hassani AS, Mirza HA: Effect of n-3 and n-6 fatty acid supplemented diets on semen quality in japanese quail (Coturnix coturnix japonica). Int J Poult Sci 2010, 9:656-663.

24. Bongalhardo DC, Leeson S, Buhr MM: Dietary lipids differentially affect membranes from different areas of rooster sperm. Poult Sci 2009, 88:1060-1069 
25. Mourvaki E, Cardinali R, Dal Bosco A, Corazzi L, Castellini C: Effects of flaxseed dietary supplementation on sperm quality and on lipid composition of sperm subfractions and prostatic granules in rabbit. Theriogenology 2010, 73:629-637.

26. Henrotte E, Kaspar V, Rodina M, Psenicka M, Linhart O, Kestemont P: Dietary $n-3 / n-6$ ratio affects the biochemical composition of Eurasian perch (Perca fluviatilis) semen but not indicators of sperm quality. Aquac Res 2010, 41:31-38.

27. Blesbois E, Lessire M, Grasseau I, Hallouis JM, Hermier D: Effect of dietary fat on the fatly acid composition and fertilizing ability of fowl semen. Biol Reprod 1997, 56:1216-1220.

28. Asturiano JF, Sorberaa LA, Carrilloa M, Zanuya S, Ramos J, Navarroa JC, Bromageb N: Reproductive performance in male European sea bass (Dicentrarchus labrax, L.) fed two PUFA-enriched experimental diets: a comparison with males fed a wet diet. Aquaculture 2001, 194:173-190.

29. Webel SK, Otto-Tice ER, Moster RL, Orr DE Jr: Effect of feeding duration of protected $\mathrm{n}-3$ polyunsaturated fatty acid $\left(\right.$ Fertilium $\left.^{\mathrm{TM}} \mathrm{M}\right)$ on litter size and embryo survival in sows. J Anim Sci 2004, 82(Suppl. 1):212. Abstr.

30. Spencer JD, Wilson L, Webel SK, Moser RL, Webel DM: Effect of feeding protected $n-3$ polyunsaturated fatty acids (Fertilium ${ }^{\mathrm{TM}}$ ) on litter size in gilts. J Anim Sci 2004, 82(Suppl. 1):211. Abstr.

31. Smits RJ, Luxford BG, Mitchell M, Nottle MB: Sow litter size is increased in the subsequent parity when lactating sows are fed diets containing $n-3$ fatty acids from fish oil. J Anim Sci 2011, 89:2731-2738.

32. Gil A, Ramirez M, Gil M: Role of Long-chain polyunsaturated fatty acids in infant nutrition. Eur J Clin Nutr 2003, 57:S31-S34.

33. Judge MP, Harel O, Lammi-Keefe CJ: Maternal consumption of a docosahexaenoic acid-containing functional food during pregnancy: benefit for infant performance on problem-solving but not on recognition memory tasks at age 9mo. Am J Clin Nutr 2007, 85:1572-1577

34. Needleman P, Turk J, Jakschik BA, Morrison AR, Lefkowith JB: Arachidonic acid metabolism. Ann Rev Biochem 1986, 55:69-102

35. Veldhuis JD, Keenan DM, Liu PY, Iranmanesh A, Takahashi PY, Nehra AX: The aging male hypothalamic-pituitary- gonadal axis: pulsatility and feedback. Mol Cell Endocrinol 2009, 299:14-22.

36. Martin GB, Walkden-Brown SW: Nutritional influences on reproduction in mature male sheep and goats. J Reprod Fertil Suppl 1995, 49:437-449.

37. Martin $G B$, Tjondronegoro $S$, Blackberry MA: Effects of nutrition on testicular size and the concentrations of gonadotrophins, testosterone and inhibin in plasma of mature male sheep. J Reprod Fertil 1994, 101:121-128.

38. Juma FT, Hayfaa MA A: The effects of Nigella sativa oil administration on some physiological and histological values of reproductive aspects of rats. Iraqi I Vet Med 2011, 35:52-60.

39. Adam CL, Findlay PA: Effect of nutrition on testicular growth and plasma concentrations of gonadotrophins, testosterone and insulin-like growth factor I (IGF-I) in pubertal male Soay sheep. J Reprod Fertil 1997, 111:121-125.

40. Bubenik GA, Brown RD, Schams D, Bartos L: The effect of ACTH on the $\mathrm{GnRH}$-induced release of $\mathrm{LH}$ and testosterone in male white-tailed deer. Comp Biochem Physiol C Pharmacol Toxicol Endocrinol 1999, 122:173-179.

41. Kiecolt-Glaser JK, Belury MA, Porter K, Beversdorf DQ, Lemeshow S, Glaser R: Depressive symptoms, omega-6:omega-3 fatty acids, and inflammation in older adults. Psychosom Med 2007, 69:217-224.

\section{doi:10.1186/1476-511X-12-33}

Cite this article as: Yan et al:: Effect of different dietary omega-3 /omega-6 fatty acid ratios on reproduction in male rats. Lipids in Health and Disease 2013 12:33.

\section{Submit your next manuscript to BioMed Central and take full advantage of:}

- Convenient online submission

- Thorough peer review

- No space constraints or color figure charges

- Immediate publication on acceptance

- Inclusion in PubMed, CAS, Scopus and Google Scholar

- Research which is freely available for redistribution

Submit your manuscript at www.biomedcentral.com/submit
C Biomed Central 